\title{
Study on change of color and some properties of high density polyethylene/organo-modified calcium carbonate composites exposed naturally at Dong Hoi - Quang Binh
}

\author{
Le Duc Minh ${ }^{1}$, Nguyen Thuy Chinh ${ }^{2}$, Nguyen Vu Giang ${ }^{2}$, Tong Cam Le', \\ Dau Thi Kim Quyen', Le Duc Giang ${ }^{3}$, Thai Hoang ${ }^{2 *}$ \\ ${ }^{I}$ Faculty of Pedagogy Natural Sciences, Ha Tinh University, 447 26/3 street, Ha Tinh, Vietnam \\ ${ }^{2}$ Institute for Tropical Technology, Vietnam Academy of Science and Technology \\ ${ }^{3}$ Faculty of Chemistry, Vinh University
}

Received 22 January 2017; Accepted for publication 28 August 2017

\begin{abstract}
This paper presents the study on the UV-Vis spectra, change of color and some properties of high density polyethylene/organo-modified calcium carbonate $\left(\mathrm{HDPE} / \mathrm{m}-\mathrm{CaCO}_{3}\right)$ composites exposed naturally in Dong Hoi district, Quang Binh province (Vietnam). From June 2014 to June 2016, the samples of $\mathrm{HDPE} / \mathrm{m}-\mathrm{CaCO}_{3}$ composites were tested naturally on outdoor shelves at Dong Hoi sea atmosphere region (at Dong Hoi, Quang Binh). The change of UVVIS spectra, color and some properties of the $\mathrm{HDPE} / \mathrm{m}-\mathrm{CaCO}_{3}$ composites depend on geographic, weather and climatic factors (solar radiation, temperature, humidity, etc.). In the UV-VIS spectra, the band at $265 \mathrm{~nm}$ showed the formation of the carbonyl groups such as ketone, lactone carbonyl and aliphatic ester which were occurred in photo-degradation process of $\mathrm{HDPE} / \mathrm{m}-\mathrm{CaCO}_{3}$ composites. The results of color change indicated the surface of the samples of $\mathrm{HDPE} / \mathrm{m}$ $\mathrm{CaCO}_{3}$ composites was lightened continuously with increasing natural exposure time and increased in total color difference value and significant loss in both redness and yellowness. $\Delta \mathrm{a}^{*}, \Delta \mathrm{b}^{*}$ values and electrical breakdown of $\mathrm{HDPE} / \mathrm{m}-\mathrm{CaCO}_{3}$ composites were decreased while their $\Delta \mathrm{l}^{*}, \Delta \mathrm{E}$, dielectric constant and dielectric loss were increased with rising natural exposure time. Dielectric constant of $\mathrm{HDPE} / \mathrm{m}-\mathrm{CaCO}_{3}$ composites was in the range of 1.75 to 2.1 and dielectric loss of $\mathrm{HDPE} / \mathrm{m}-\mathrm{CaCO}_{3}$ composites went up from 1.7 to 3.2 for 0 to 24 months. The electrical breakdown of $\mathrm{HDPE} / \mathrm{m}-\mathrm{CaCO}_{3}$ composites reduced due to the decrease in the relative crystalline degree of the samples caused by the scission photo-degradation of $\mathrm{HDPE}$ macromolecules in $\mathrm{HDPE} / \mathrm{m}-\mathrm{CaCO}_{3}$ composites for natural exposure time.
\end{abstract}

Keywords. $\mathrm{HDPE} / \mathrm{CaCO}_{3}$ composites, photo-degradation, natural exposure, color change, electric properties, UVVis spectroscopy.

\section{INTRODUCTION}

High-density polyethylene (HDPE) is currently the most widely used commercial polymer due to its superior mechanical and physical properties. However, its toughness, weather resistance, processability, and environmental stress cracking resistance are not good enough, which have thus limited its application in many high-technology fields. One measure to improve its properties is reinforcement with some fillers [1]. Inexpensive inorganic substances such as calcium carbonate $\left(\mathrm{CaCO}_{3}\right)$, mica, wollastonite, glass fiber, glass beads, jute, and silica $\left(\mathrm{SiO}_{2}\right)$ are widely used as fillers to improve mechanical and thermal properties of polymers in the plastic industry. In recent years micro-size fillers have attracted great interest, both in industry and in academia because they often exhibit remarkable improvement in properties of materials [2].

HDPE filled with mineral particles also improves dimensional stability, opacity, and barrier properties. $\mathrm{CaCO}_{3}$ is the largest volume mineral used in the polymer industry because of its low cost and abundance. It is available globally in a variety of particle shapes, purities, and sizes (macro, micro, and nano). However, because of its higher polar nature and higher surface areas, $\mathrm{CaCO}_{3}$ is difficult to disperse and stabilize in a polymer matrix. Poor dispersion and adhesion of filler lead to a composite with poor final physical properties [3, 4]. Therefore, organo-modification of surface of $\mathrm{CaCO}_{3}$ can help to improve the interaction and dispersion of $\mathrm{CaCO}_{3}$ into the polymer matrix [5-7]. 
The study on the degradability of linear polyolefins under natural exposure testing was reported by Telmo Ojeda [8]. This study showed that in less than one year of testing, the mechanical properties of all samples decreased virtually to zero, as a consequence of severe oxidative degradation, that resulted in substantial reduction in molar mass accompanied by a significant increase in content of carbonyl groups. Rui Yang et al. have studied the natural photo-oxidation of HDPE composites, with several inorganic fillers. They concluded that some inorganic fillers such as $\mathrm{CaCO}_{3}$ and wollastonite, can stabilize HDPE. The surfaces of the composites after natural exposure testing became rough and with cracks. A seriously damaged surface did not definitely correspond to a great oxidation degree. The remaining volatile oxidation products of the photo-oxidized composites were proven to be mostly a series of n-alkanes [9]. The study on the effect of natural exposure testing on tensile properties of kenaf reinforced HDPE composites was reported by A.H. Umar [10]. Due to better stiffness, Young modulus of HDPE composites is much higher than neat HDPE. The micro-cracking on the surface of HDPE composites can be observed after 200 hours of testing.

Recently, we have studied the degradation and stability of $\mathrm{HDPE} / \mathrm{m}-\mathrm{CaCO}_{3}$ composites under natural weather condition on outdoor shelves in Dong Hoi sea atmosphere region (Quang Binh province) to evaluate the change of their morphology and properties. In the Fourier Transform Infrared spectra of the exposed samples, the absorption peak around $1735 \mathrm{~cm}^{-1}$ characterizes the stretching vibration of carbonyl group formed during natural exposure. The tensile strength and elongation at break of $\mathrm{HDPE} / \mathrm{m}-\mathrm{CaCO}_{3}$ composites were reduced significantly while their Young modulus, the number of cracks and size of cracks on the surface of the samples were increased with increasing natural exposure time. The melting enthalpy, relative crystalline degree of $\mathrm{HDPE} / \mathrm{m}$ $\mathrm{CaCO}_{3}$ composites were slightly increased during the first 9 months of natural exposure while their melting temperature and initial degradation temperature were decreased [11].

This study reports the results of change in UVVis spectra, color, electrical properties of HDPE/m$\mathrm{CaCO}_{3}$ composites exposed naturally in Dong Hoi, Quang Binh. Here, we chose Dong Hoi, Quang Binh to investigate the change in properties and morphology of $\mathrm{HDPE} / \mathrm{m}-\mathrm{CaCO}_{3}$ because Dong Hoi has not only the sea climate but also draconic climate. This is typical climate at the sea atmosphere region in the north - middle provinces. The influence of natural exposure time and weather factors on the above changes $\mathrm{HDPE} / \mathrm{m}-\mathrm{CaCO}_{3}$ composites were evaluated and discussed.

\section{EXPERIMENTAL}

\subsection{Materials}

The materials used in this work were a HDPE (Daelim, Korea) with melting flow index, $\mathrm{MFI}_{190^{\circ} \mathrm{C} / 2.16 \mathrm{~kg}}$ of $1.20 \mathrm{~g} . \mathrm{min}^{-1}$, and its density of 0.937 g. $\mathrm{cm}^{-3} ; \mathrm{CaCO}_{3}$ powder with density of 2.7 g. $\mathrm{cm}^{-3}$ (Minh Duc Chemical Stockshare Co.) was modified by $0.5 \mathrm{wt} \%$ of stearic acid in solid state using high intermixer (SHR-100A, Shanghai China) for 90 minutes at $60-65^{\circ} \mathrm{C}$ and mixing speed of 750 $800 \mathrm{rpm}$.

\subsection{Preparation of $\mathrm{HDPE} / \mathrm{m}-\mathrm{CaCO}_{3}$ composites}

The HDPE/m- $\mathrm{CaCO}_{3}$ (wt./wt.) composites were prepared by melt-mixing in a Hake internal mixer at $160{ }^{\circ} \mathrm{C}$ for 5 minutes at Institute for Tropical Technology (ITT), Vietnam Academy of Science and Technology (VAST). Immediately after meltmixing, the $\mathrm{HDPE} / \mathrm{m}-\mathrm{CaCO}_{3}$ composites were pressed by hydraulic heat press machine at a temperature of $160{ }^{\circ} \mathrm{C}$ and the pressure of $5 \mathrm{MPa}$ to form sheets with thickness from 1 to $1.2 \mathrm{~mm}$.

\subsection{Natural exposure of $\mathrm{HDPE} / \mathrm{m}-\mathrm{CaCO}_{3}$ composites}

The samples of $\mathrm{HDPE} / \mathrm{m}-\mathrm{CaCO}_{3}$ composites were exposed starting from June 2014 to June 2016 on outdoor testing shelves at the Natural Weathering Station of the Institute for Tropical Technology in Dong Hoi sea atmosphere region (Quang Binh, Vietnam). Inclining angle of the shelf in comparison with the ground was 45 degree as typically shown in Figure 1, and total exposure time of the samples was 24 months.
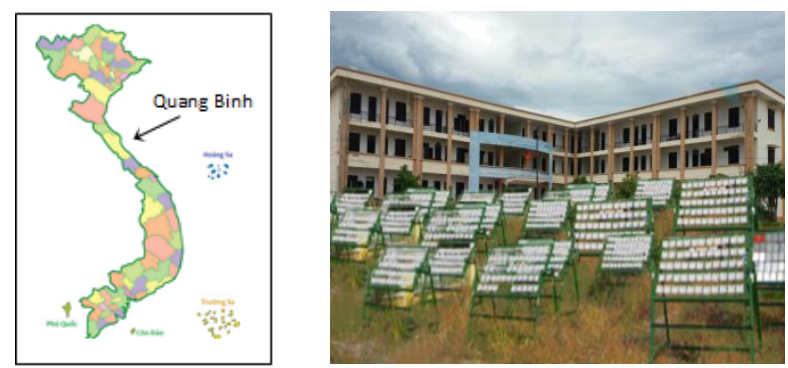

Figure 1: View of outdoor exposure testing shelves at Dong Hoi sea atmosphere region 
After every three months, the samples were withdrawn and stored under standard conditions before determining their properties and morphology. The abbreviate samples were M0, M3, M6, M9, M12, M15, M18, M21, M24 corresponding to 3, 6, $9,12,15,18,21,24$ months of natural expose, respectively.

\subsection{Characterizations}

\subsubsection{UV-Vis analysis}

UV-Vis spectra of $\mathrm{HDPE} / \mathrm{m}-\mathrm{CaCO}_{3}$ composites were recorded on a CINTRA 40 (USA) UV-Vis GBC scanning spectrophotometer in the range 200$500 \mathrm{~nm}$ at ITT, VAST.

\subsubsection{Color measurements}

The color parameters of $\mathrm{HDPE} / \mathrm{m}-\mathrm{CaCO}_{3}$ composites were determined by a ColourTec PCM $\left(\mathrm{PSM}^{\mathrm{TM}}\right.$, United State) according to ASTM D224489 standard. The total color difference $(\Delta \mathrm{E})$ of the samples was calculated using the following equations.

$$
\Delta E=\sqrt{\Delta L^{* 2}+\Delta a^{*^{2}}+\Delta b^{*^{2}}}
$$

Where, $\Delta \mathrm{L}^{*}=\mathrm{L}^{*}-\mathrm{L}_{0} ; \Delta \mathrm{a}^{*}=\mathrm{a}^{*}-\mathrm{a}_{0} ; \Delta \mathrm{b}^{*}=\mathrm{b}^{*}-\mathrm{b}_{0}$;

And $\mathrm{L}^{*}$ is a measurement of brightness $\left(\Delta \mathrm{L}^{*}>0\right.$ for light, $\Delta \mathrm{L}^{*}<0$ for dark); $\mathrm{a}^{*}$ is a measurement of redness or greenness $\left(\Delta \mathrm{a}^{*}>0\right.$ for red, $\Delta \mathrm{a}^{*}<0$ for green); $b^{*}$ is a measurement of yellowness or blueness $\left(\Delta b^{*}>0\right.$ for yellow, $\Delta b^{*}<0$ for blue); $L^{*}$, $a^{*}$ and $b^{*}$ are the color parameters of the natural exposed sample; $\mathrm{L}_{0}, \mathrm{a}_{0}$ and $\mathrm{b}_{0}$ are the color parameters of the unexposed sample. For each sample, the color parameters were measured at ten different positions of the sample to obtain the average value. The above measurements were performed at ITT, VAST.

\subsubsection{Electric properties}

The dielectric parameters of $\mathrm{HDPE} / \mathrm{m}-\mathrm{CaCO}_{3}$ composites (dielectric constant - $\varepsilon$ ' and dielectric loss $-\tan \delta$ ) were measured at $1 \mathrm{kHz}$ by TR-10C machine (Ando, Japan) according to ASTM D150 standard. The volume resistivity and surface resistivity were conducted on TR 8491 machine (Takeda, Japan) according to ASTM D257. The electrical breakdown was carried out on Til-Aii 70417 machine (Russia) according to ASTM D149-64 standard. The above experiments were performed at $25{ }^{\circ} \mathrm{C}$ and humidity about $60 \%$ at ITT, VAST.

\section{RESULTS AND DISCUSSION}

\subsection{UV-Vis spectra}

The UV-Vis spectra of $\mathrm{HDPE} / \mathrm{m}-\mathrm{CaCO}_{3}$ composites according to natural exposure time at Dong Hoi (Quang Binh) were presented in figure 2. The UVVis spectra showed an increase of the absorption intensity of HDPE in the composites between 200 and $300 \mathrm{~nm}$ wavenumber. In the UV-Vis spectrum of initial sample (M0 sample), there was one very strong absorption band at $226 \mathrm{~nm}$. The absorption at $226 \mathrm{~nm}$ must be associated with the $\pi-\pi^{*}$ transition of the ethylenic group of the $\alpha, \beta$-unsaturated carbonyl of impurity chromophores of the enone type in photo-oxidation degraded HDPE. The presence of these chromophores had been identified in the previous studies results [11]. For the exposed samples, the UV-Vis spectra also had the absorption band at $226 \mathrm{~nm}$. Interestingly, the formation of a very broad absorption centred at $265 \mathrm{~nm}$ characterized for the carbonyl groups in HDPE when increasing natural exposure time. The results from the UV-Vis spectra indicated the formation of the carbonyl groups such as ketone, lactone carbonyl and aliphatic ester which were occurring in photodegradation process of $\mathrm{HDPE} / \mathrm{m}-\mathrm{CaCO}_{3}$ composites.

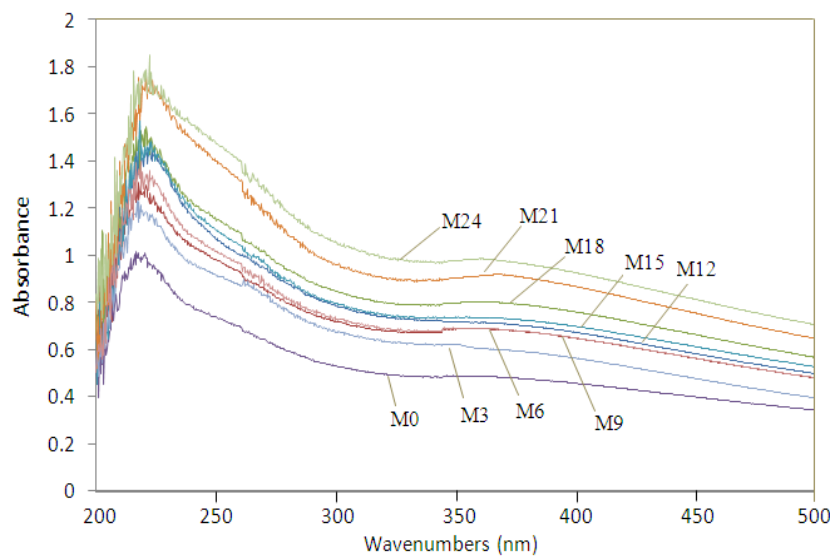

Figure 2: UV-Vis spectra of $\mathrm{HDPE} / \mathrm{m}-\mathrm{CaCO}_{3}$ composites according to natural exposure time

The chain scission of the HDPE in the composites matrix by photo-oxidative degradation of the polymer via Norrish 1 and 2 reactions. If degradation of the carbonyl groups proceeds according to the Norrish 1 reaction, the formed free radicals can attack the polyolefin (scheme 1) [12], which may lead to termination via crosslinking or chain scission. If the degradation proceeds according to the Norrish 2 reaction, carbonyl groups and terminal vinyl groups are produced (scheme 2) and chain scission occurs [12]. The ketones, carboxylic 
acids, and vinyl groups are the three major functional groups that accumulate with the photodegradation of HDPE macromolecules in HDPE/m$\mathrm{CaCO}_{3}$ composites [13]. The formation of carbonyl groups and vinyl groups can be remarks of HDPE chain scission.

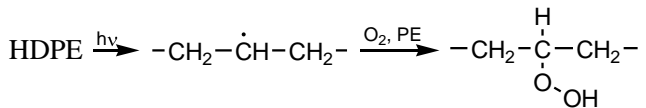

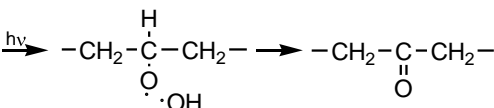

$$
\begin{aligned}
& \stackrel{\text { hvv }}{\rightarrow}-\mathrm{CH}_{2}-\underset{\mathrm{O}}{\mathrm{C} \cdot}+\mathrm{CH}_{2}-;-\underset{\mathrm{O}}{\mathrm{CH}_{2}-\mathrm{C}} \rightarrow--\dot{\mathrm{C}} \mathrm{H}_{2}+\mathrm{CO}
\end{aligned}
$$

Scheme 1: Norrish Type 1 reaction for the photo-degradation of HDPE [12]

$$
\begin{aligned}
& \mathrm{HDPE} \stackrel{h_{\mathrm{W}}}{\longrightarrow}-\mathrm{CH}_{2}-\mathrm{CH}_{2}-\dot{\mathrm{C}} \mathrm{H}-\mathrm{CH}_{2}-\mathrm{CH}_{2}-\stackrel{\mathrm{O}_{2}, \mathrm{PE}}{\longrightarrow}
\end{aligned}
$$

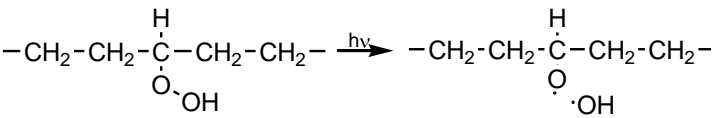

$$
\begin{aligned}
& \rightarrow-\mathrm{CH}_{2}-\mathrm{CH}_{2}-\mathrm{C}_{\mathrm{O}}-\mathrm{CH}_{2}-\mathrm{CH}_{2}-\stackrel{\mathrm{hv}}{\longrightarrow}-\mathrm{CH}=\mathrm{CH}_{2}+\underset{\mathrm{O}}{-\mathrm{C}}-\mathrm{CH}_{3}
\end{aligned}
$$

Scheme 2: Norrish Type 2 reaction for the photo-degradation of HDPE [12]

\subsection{Color change}

The change of surface color of $\mathrm{HDPE} / \mathrm{m}-\mathrm{CaCO}_{3}$ composites depends on their structure and composition (the chemical composition change leads to the changes in electric, thermal, and color properties) [14]. The change in values for three color parameters $\left(\Delta \mathrm{L}^{*}, \Delta \mathrm{a}^{*}\right.$ and $\left.\Delta \mathrm{b}^{*}\right)$ as well as the total color change $(\Delta \mathrm{E})$ of the composites as a function of natural exposure time was displayed in table 1 and figure 3 .

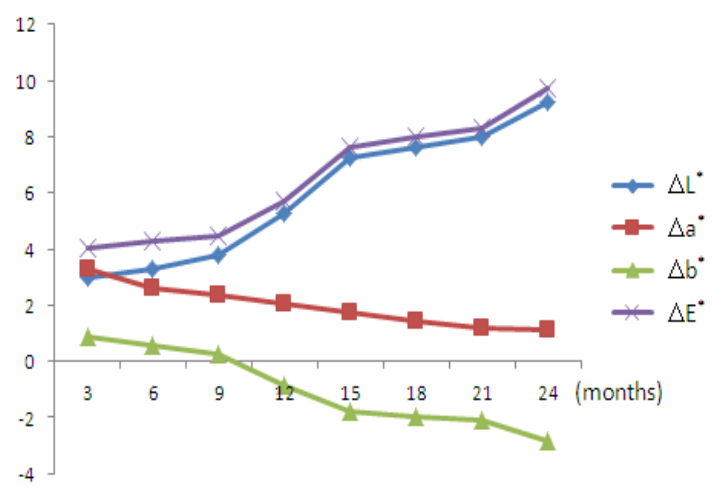

Figure 3: The $\Delta \mathrm{a}^{*}, \Delta \mathrm{b}^{*}, \Delta \mathrm{L}^{*}$ and $\Delta \mathrm{E}$ value of $\mathrm{HDPE} / \mathrm{m}-\mathrm{CaCO}_{3}$ composites according to natural exposure time

The surface of the samples of $\mathrm{HDPE} / \mathrm{m}-\mathrm{CaCO}_{3}$ composites was lightened continuously, the $\Delta \mathrm{L}^{*}$ and
$\Delta \mathrm{E}$ values were increased with increasing natural exposure time. The changes in $\Delta \mathrm{E}$ values for the samples were found to be consistent with the change in $\Delta \mathrm{L}^{*}$ values. The results of color change indicated that the surface of the samples of $\mathrm{HDPE} / \mathrm{m}-\mathrm{CaCO}_{3}$ composites was faded continuously with increasing natural exposure time expressed by a constant increase in $\Delta \mathrm{L}^{*}$ value and significant loss in both redness and yellowness. This phenomenon may be due to the change in morphology and existence of double bonds, chromophore groups and heterogeneous structures inside the HDPE macromolecules during photodegradation $\mathrm{HDPE} / \mathrm{m}$ $\mathrm{CaCO}_{3}$ composites. These groups affect the visible light absorbability, leading to the variation in visual color of the composites.

The $\Delta \mathrm{b}^{*}$ value of $\mathrm{HDPE} / \mathrm{m}-\mathrm{CaCO}_{3}$ composites was decreased significantly with natural exposure time. This decrease indicated a loss in yellowness. Two distinguished periods of lightness decrease: one between the third and ninth months (from September 2014 to March 2015) and another between the fifteenth and twenty-first months (from September 2015 to March 2016). After 3 and 9 months of natural exposure testing, the $\Delta \mathrm{b}^{*}$ values of $\mathrm{HDPE} / \mathrm{m}$ $\mathrm{CaCO}_{3}$ composites were 0.86 and 0.26 , respectively. Similarly, when natural exposure time was reached up to 15 and 21 months, the $\Delta b^{*}$ of $\mathrm{HDPE} / \mathrm{m}-\mathrm{CaCO}_{3}$ composites were -1.8 and -2.08 , respectively. The winter and spring months were characterized by gradual increase of rainfall and decrease of solar radiation (table 2). The significant decrease of the $\Delta b^{*}$ value was observed for the samples exposed from 9 to 15 months and from 21 to 24 months. After 9 and 15 months of natural exposure testing, the $\Delta b^{*}$ of $\mathrm{HDPE} / \mathrm{m}-\mathrm{CaCO}_{3}$ composites were 0.26 and -1.80 , respectively. When natural exposure time was reached up to 21 and 24 months, the $\Delta b^{*}$ of $\mathrm{HDPE} / \mathrm{m}-\mathrm{CaCO}_{3}$ composites are -2.08 and -2.85 , respectively (table 1 ). In the summer, the average temperature/month and average sunny hours/month are higher, thus the samples have been affected by solar radiation more strongly. This caused the faster photo-degradation of $\mathrm{HDPE} / \mathrm{m}-\mathrm{CaCO}_{3}$ composites, thus, their $\Delta b^{*}$ values were decreased significantly.

The average temperature, the relative humidity, the total rainfall and total hours of sunlight at Dong Hoi (Quang Binh) in the period from 2014-2016 were demonstrated in table 2 . It is clearly seen that, from ninth to fifteenth months and from twenty-first to twenty-fourth months of natural exposure, the highest temperature is from 27.2 to $38.6{ }^{\circ} \mathrm{C}$ and 35.2 to $36.5^{\circ} \mathrm{C}$, total sunlight hours were quite high, 1208 and 493 hours, respectively. The high intensity of 
solar radiation could make a significant contribution $\mathrm{HDPE} / \mathrm{m}-\mathrm{CaCO}_{3}$ composites.

to the photodegradation in amorphous part of

Table 1: The change of $\Delta \mathrm{a}^{*}, \Delta \mathrm{b}^{*}, \Delta \mathrm{L}^{*}$ and $\Delta \mathrm{E}^{*}$ value of $\mathrm{HDPE} / \mathrm{m}-\mathrm{CaCO}_{3}$ composites according to natural exposure time

\begin{tabular}{|c|c|c|c|c|c|c|c|c|}
\hline Samples & M3 & M6 & M9 & M12 & M15 & M18 & M21 & M24 \\
\hline$\Delta \mathrm{a}^{*}$ & 3.27 & 2.63 & 2.33 & 2.05 & 1.71 & 1.41 & 1.21 & 1.11 \\
\hline$\Delta \mathrm{b}^{*}$ & 0.86 & 0.59 & 0.26 & -0.86 & -1.80 & -1.96 & -2.08 & -2.85 \\
\hline$\Delta \mathrm{L}^{*}$ & 2.99 & 3.31 & 3.77 & 5.27 & 7.22 & 7.62 & 7.98 & 9.24 \\
\hline$\Delta \mathrm{E}$ & 4.03 & 4.26 & 4.44 & 5.71 & 7.64 & 8.00 & 8.33 & 9.73 \\
\hline
\end{tabular}

Table 2: Climate and weather database at Dong Hoi (Quang Binh) from June 2014 to June 2016

\begin{tabular}{|c|c|c|c|c|c|c|c|c|c|c|}
\hline \multicolumn{2}{|c|}{ Times } & $\begin{array}{l}\text { Ttb } \\
\left({ }^{\circ} \mathrm{C}\right)\end{array}$ & $\begin{array}{c}\mathrm{Tx} \\
\left({ }^{\circ} \mathrm{C}\right)\end{array}$ & $\begin{array}{c}\mathrm{R} \\
(\mathrm{mm})\end{array}$ & $\begin{array}{c}\mathrm{Rx} \\
(\mathrm{mm})\end{array}$ & $\begin{array}{l}\text { Utb } \\
(\%)\end{array}$ & $\begin{array}{c}\mathrm{E} \\
(\mathrm{mm})\end{array}$ & $\begin{array}{c}\mathrm{S} \\
(\mathrm{h})\end{array}$ & $\begin{array}{l}\text { St } \\
\text { (d) }\end{array}$ & $\begin{array}{l}\text { CC } \\
\text { (d) }\end{array}$ \\
\hline \multirow{7}{*}{2014} & June & 30.9 & 39 & 78 & 41 & 67 & 163 & 191 & 22 & 0 \\
\hline & July & 30.1 & 37.5 & 85 & 31 & 71 & 137 & 220 & 12 & 0 \\
\hline & August & 29.6 & 38.5 & 132 & 60 & 72 & 134 & 176 & 11 & 0 \\
\hline & September & 29.6 & 38.5 & 132 & 60 & 72 & 134 & 176 & 11 & 0 \\
\hline & October & 25.6 & 32 & 605 & 189 & 87 & 57 & 129 & 0 & 0 \\
\hline & November & 24.2 & 30 & 344 & 160 & 88 & 48 & 106 & 0 & 0 \\
\hline & December & 19.2 & 25.8 & 160 & 48 & 82 & 70 & 35 & 0 & 0 \\
\hline \multirow{12}{*}{2015} & January & 18.8 & 25 & 84 & 42 & 84 & 55 & 130 & 0 & 0 \\
\hline & February & 20.7 & 27.2 & 40 & 9 & 91 & 28 & 64 & 0 & 0 \\
\hline & March & 24.2 & 36.7 & 32 & 24 & 90 & 39 & 100 & 0 & 0 \\
\hline & April & 25.6 & 41 & 206 & 133 & 85 & 72 & 173 & 8 & 0 \\
\hline & May & 31 & 40.5 & 9 & 6 & 70 & 176 & 298 & 18 & 0 \\
\hline & June & 30.9 & 39.5 & 73 & 36 & 69 & 153 & 290 & 22 & 0 \\
\hline & July & 29.1 & 39.3 & 88 & 15 & 72 & 136 & 106 & 9 & 0 \\
\hline & August & 29.6 & 38.6 & 36 & 19 & 76 & 114 & 241 & 8 & 0 \\
\hline & September & 28.8 & 38.6 & 567 & 194 & 81 & 93 & 204 & 6 & 0 \\
\hline & October & 25.8 & 32.8 & 95 & 36 & 81 & 79 & 170 & 0 & 0 \\
\hline & November & 25.5 & 31 & 339 & 68 & 86 & 49 & 143 & 0 & 0 \\
\hline & December & 21.2 & 29.2 & 79 & 47 & 85 & 55 & 75 & 0 & 0 \\
\hline \multirow{6}{*}{2016} & January & 19.8 & 27.3 & 70 & 44 & 89 & 35 & 48 & 0 & 0 \\
\hline & February & 17.6 & 35.2 & 8 & 4 & 80 & 70 & 82 & 1 & 0 \\
\hline & March & 20.6 & 28.5 & 16 & 4 & 89 & 36 & 80 & 0 & 0 \\
\hline & April & 25.7 & 40 & 53 & 36 & 87 & 53 & 169 & 3 & 0 \\
\hline & May & 28.4 & 36.5 & 75 & 38 & 80 & 92 & 244 & 3 & 0 \\
\hline & June & 31.0 & 38.5 & 119 & 63 & 70 & 117 & 260 & 13 & 0 \\
\hline
\end{tabular}

$\mathrm{T}_{\mathrm{tb}}, \mathrm{T}_{\mathrm{x}}$ : Average and highest temperature; $\mathrm{R}, \mathrm{R}_{\mathrm{x}}$ : Rainy total and highest rainy quantity in day; $\mathrm{U}_{\mathrm{tb}}$ : Average humidity; e: Steam quantity; S: Sunny hours; St: Storm; CC: Day numbers have drizzle.

\subsection{Electric properties}

\subsubsection{Dielectric parameters}

The frequency dependence of dielectric constant of
$\mathrm{HDPE} / \mathrm{m}-\mathrm{CaCO}_{3}$ composites according to natural exposure time was shown in figure $4 \mathrm{a}$. It can be seen that the effective dielectric constant of the M0 sample was very weakly dependent on frequency, which is the typical characteristic of non-polar 
polymers. The M0 sample contained non- dipolar units and there were not frequency characteristics in the range of $100-10^{6} \mathrm{~Hz}$. For the exposed samples, the interfacial polarization can cause an increase of dielectric constant when compared with the M0 sample. When the chains of HDPE in HDPE/m$\mathrm{CaCO}_{3}$ composites were scissed, the free volumes could be decreased and may cause the increase of dielectric constant. Additionally, it was caused by the formation of the carbonyl groups such as ketone, lactone carbonyl and aliphatic ester occurring in photo-degradation process of $\mathrm{HDPE} / \mathrm{m}-\mathrm{CaCO}_{3}$ composites. When increasing natural exposure time, the charge carriers in composites were increased. This contributed to the rise of dielectric constant of the samples.

The dielectric loss of $\mathrm{HDPE} / \mathrm{m}-\mathrm{CaCO}_{3}$ composites was increased with increasing natural exposure time and frequency because a higher frequency voltage can yield higher electrical conductivity as shown in figure $4 \mathrm{~b}$. Unlike the dependence of dielectric constant, an unclear correlation of dielectric loss which can be stated (the dielectric loss of the samples can increase or decrease when increasing natural exposure time) and immobility of charge carriers in the samples. There were two competitive factors that affect the dielectric loss of the samples such as hindrance in charge transport and the incorporation of charge. The incorporation of large volume fraction of interfaces and polymer chain entanglement which in turn cause immobility of charge carriers or reduction in electrical conductivity, and thus causing a reduction of dielectric loss. On the other hand, the agglomeration of volume fraction can also result in an apparent reduction of interface area of the samples. Therefore, the effect of immobility of charge carriers on reduction in electrical conductivity is far less important than the influence of charge carriers, which causes an increase of dielectric loss of the samples.

\subsubsection{Electrical breakdown voltage}

The electrical breakdown voltage data of HDPE/m$\mathrm{CaCO}_{3}$ composites were performed in table 3. The value of electrical breakdown voltage of the samples was decreased gradually with increasing natural exposure time. This observation is of vital importance for engineering application because the dielectric rupture always occurs at the weakest points. In other words, the real dielectric strength of the samples is determined by the weakest part of their insulation.
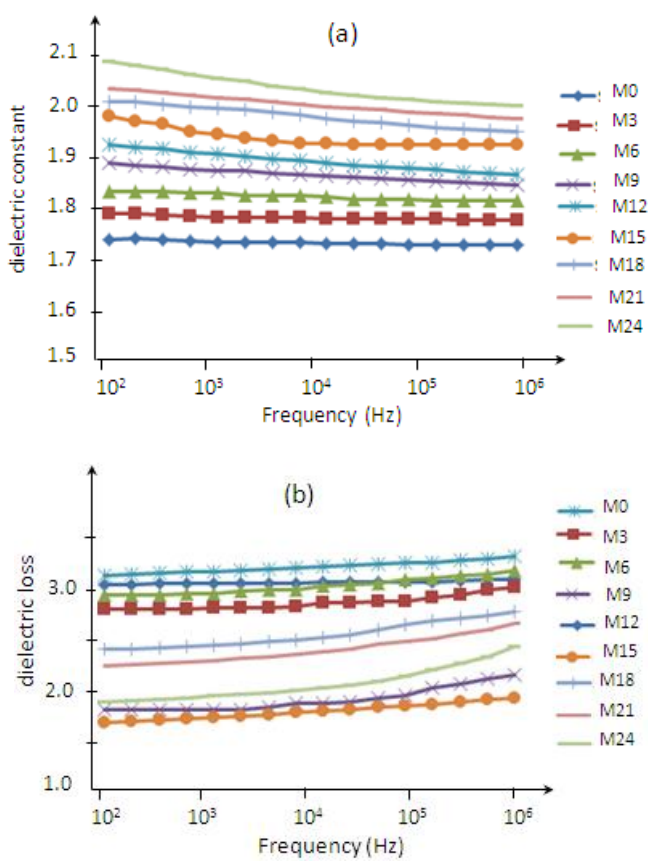

Figure 4: Frequency dependence of dielectric constant (a) and dielectric loss (b) of HDPE/m$\mathrm{CaCO}_{3}$ composites according to natural exposure time

Firstly, when increasing natural exposure time, the relative crystalline degree of the samples was reduced. This can be explained by the scission photo-degradation of HDPE macromolecules in $\mathrm{HDPE} / \mathrm{m}-\mathrm{CaCO}_{3}$ composites leading to decrease crystalline regions of $\mathrm{HDPE} / \mathrm{m}-\mathrm{CaCO}_{3}$ composites as shown in previous research [11]. In the result, the intrinsic strength of the samples was decreased. Secondly, the mobility of charges in the HDPE/m$\mathrm{CaCO}_{3}$ composite insulation is much higher with increasing natural exposure time. Therefore, the charges are wider distributed in the $\mathrm{HDPE} / \mathrm{m}-\mathrm{CaCO}_{3}$ composites and the screening effect is less pronounced. The above reasons make decrease of the electrical breakdown voltage of the composites according to natural exposure time (table 3 ).

Table 3: Electrical breakdown voltage data of $\mathrm{HDPE} / \mathrm{m}-\mathrm{CaCO}_{3}$ composites according to natural exposure time

\begin{tabular}{|c|c|c|c|c|c|c|c|c|c|}
\hline Samples & M0 & M3 & M6 & M9 & M12 & M15 & M18 & M21 & M24 \\
\hline $\mathrm{E}(\mathrm{kV} / \mathrm{mm})$ & 24.17 & 21.89 & 21.55 & 18.33 & 17.54 & 17.04 & 16.46 & 15.68 & 14.39 \\
\hline
\end{tabular}




\section{CONCLUSIONS}

In this work, the influence of climate and weather factors and natural exposure time at Dong Hoi (Quang Binh) on UV-Vis spectra, the change of color, and electric properties of $\mathrm{HDPE} / \mathrm{m}-\mathrm{CaCO}_{3}$ composites were investigated. The UV-Vis spectra showed the formation of carbonyl groups and vinyl groups in HDPE macromolecules of the composites by their photo-degradation. The surface of the composites was lightened continuously, the $\Delta \mathrm{L}^{*}$ and $\Delta \mathrm{E}^{*}$ values were increased with increasing natural exposure time. There was significant loss in both redness and yellowness of the composites. In the summer, the composites were affected by solar radiation more strongly, so the yellowness was decreased significantly. The dielectric constant, dielectric loss of the composites were increased and their electrical breakdown voltage was reduced with increasing natural exposure time.

Acknowledgement. The authors thank Vietnam Academy of Science and Technology for supporting this research and National Center of HydroMeteorological Service for providing the weather and climate data.

\section{REFERENCES}

1. S. C. Tjong, S. P. Bao. Crystallization regime characteristics of exfoliated polyethylene/vermiculite nanocomposites. Journal of Polymer Science Part B: Polymer Physics, 43, 253-261 (2005).

2. S. S. Ray, M. Okamoto. Polymer/layered silicate nanocomposites: a review from preparation to processing. Journal of Polymer Science, 28, 15391641 (2003).

3. Y. Wang, J. Shi, L. Han, F. Xiang. Crystallization and mechanical properties of $T-\mathrm{ZnOw} / \mathrm{HDPE}$ composites. Materials Science and Engineering A, 501, 220-228 (2009).

4. A. S. Argon, Z. Bartczak, R. E. Cohen, O. K. Muratoglu. Toughening of Plastics: Advances in Modeling and Experiments. Symposium Series 759. Washington, DC: American Chemical Society, 98 (2000).
5. S. Sahebiana, S. M. Zebarjada, J. V. Khakia, S. A. Sajjadi. The effect of nano-sized calcium carbonate on thermodynamic parameters of HDPE, Journal Mater Process Technol., 209, 1310 (2009).

6. S. M. Zebarjad, S. A. Ajjadi. On the strain rate sensitivity of $\mathrm{HDPE} / \mathrm{CaCO}_{3}$ nanocomposites. Materials Science and Engineering A, 475, 365-367 (2008).

7. X. Tingxiu, L. Hongzhi, O. Yuchun, Y. Guisheng. Synergistically toughening high density polyethylene with calcium carbonate and elastomer, Journal of Polymer Science Part B: Polymer Physics, 43, 3213 (2005).

8. T. Ojeda, A. Freitas, K. Birck, E. Dalmolin, R. Jacques, F. Bento, F. Camargo. Degradability of linear polyolefins under natural weathering, Polymer Degradation and Stability, 96, 703-707 (2011).

9. Rui Yang, Jian Yu, Ying Liu, Kunhua Wang. Effects of inorganic fillers on the natural photo-oxidation of high-density polyethylene, Polymer Degradation and Stability, 88, 333-340 (2005).

10. A. H. Umar, E. S. Zainudin, S. M. Sapuan. Effect of natural weathering on tensile properties of kenaf reinforced HDPE composites, Journal of Mechanical Engineering and Sciences, 2, 198-205 (2012).

11. Le Duc Minh, Nguyen Thuy Chinh, Nguyen Thi Thu Trang, Nguyen Vu Giang, Tran Huu Trung, Mai Duc Huynh, Tran Thi Mai, Le Duc Giang, Thai Hoang. Study on change of some characters and morphology of polyethylene compound exposed naturally in Dong Hoi - Quang Binh, Vietnam, Journal of Chemistry, 54(2), 153-159 (2016).

12. M. S. Nicole, M. M. Laurent. Surface chemistry changes of weathered HDPE/wood-flour composites studied by XPS and FTIR spectroscopy, Polymer Degradation and Stability, 86, 1-9 (2004).

13. L. C. Mendes, E. S. Rufino, F. O. C de Paula, A.C. Torres. Mechanical, thermal and microstructure evalution of HDPE after wearthing in Rio de Janeiro City, Polymer Degradation and Stability, 79(3), 371383 (2003).

14. V. Sharratt, A. Callum, S. Hill, P. Darwin, R. Kint. A study of early colour change due to simulated accelerated sunlight exposure in Scots pine (Pinus sylvestris), Polymer Degradation and Stability, 94, 1589-1594 (2009).

\section{Corresponding author: Thai Hoang}

Institute for Tropical Technology

Vietnam Academy of Science and Technology

No. 18, Hoang Quoc Viet Road, Cau Giay Dist., Ha Noi

E-mail: hoangth@itt.vast.vn. 